\title{
The impact of school structures and cultures on change in teaching and learning: the case of languages
}

\author{
Anthony J. Liddicoat ${ }^{1}$ (D) Angela Scarino $^{2} \cdot$ Michelle Kohler $^{3}$
}

Received: 24 February 2017 /Revised: 13 June 2017 / Accepted: 27 June 2017 / Published online: 9 August 2017

(C) The Author(s) 2017. This article is an open access publication

\begin{abstract}
This paper reports on a project of structural and curriculum change in the Languages learning area in three Australian schools that implemented new models of Languages provision over a 3-year period and seeks to examine the ways that school cultures influence processes of change. The project adopted a qualitative collective case study approach that involved collaboration between teachers, school leadership and the research team on activities related to implementing the models, including a contextual analysis of policies and structures, collaborative curriculum planning and implementation, planning of interventions relevant to each site, monitoring, and ongoing evaluation and annual reporting. It also collected structural data in the form of school profiles, including information about the school context and learner groups, curriculum data, including program documentation, resources, student work samples, tasks and assessment data, and teacher and student evaluation data. Interviews were conducted with participating teachers, school leaders and students on a continuous basis, gathering each participant's perspectives on the process of change over time. The paper examines
\end{abstract}

Anthony J. Liddicoat

A.Liddicoat@warwick.ac.uk

Angela Scarino

Angela.Scarino@unisa.edu.au

Michelle Kohler

michelle.kohler@flinders.edu.au

1 Centre for Applied Linguistics, University of Warwick, Coventry CV4 7AL, UK

2 Research Centre for Languages and Cultures, University of South Australia, GPO Box 2471, Adelaide, SA 5001, Australia

3 College of Humanities, Arts and Social Sciences,, Flinders University, GPO Box 2100, Adelaide, SA 5001, Australia the ways that the culture of schools, and in particular the structures that existed in the schools in relation to timetabling, the organisation of curriculum, the planning and enactment of teaching, learning and assessment and the approach to staffing, influenced what was possible in terms of change and ultimately the sustainability of change, particularly in relation to a learning area that is perceived to be 'specialist'.

Keywords Languages education · Curriculum change · Schools culture $\cdot$ School structures

\section{Introduction}

This article reports on a curriculum innovation project conducted in three schools in Australia that involved a close collaboration between the researchers and the schools involved over a 3-year period. The project itself aimed to investigate ways of increasing the intensity of language learning in terms of time on task and the inclusion of significant curriculum content. The curriculum change involved the adoption of models to increase time spent in language learning, chosen by the schools from among options developed by the research team. The choice of model to be adopted and the form that the model would take were determined by the schools as a joint initiative of language teachers and school leaders. The development of the curriculum change involved the development of new teaching and learning programs for languages, with accompanying materials, pedagogies and assessment, but also involved finding ways of integrating the new models of provision into the existing curriculum of the schools.

The cultural nature of educational change is now widely recognised (e.g. Deal and Peterson 2016; Eilers and Camacho 2007; Engels et al. 2008; Fernandez 2000; Gleeson et al. 2002; Nevalainen et al. 2017; Seashore Louis and Lee 2016). 
Education happens within systems of structures that are cultural, social and organisational, and the structural settings and their management are integrated with ideology. They are not simply structures but structures that have come to be imbued with meaning. As Fullan (2016: 19) observes, all instances of educational change occur within a "familiar, reliable construction of reality" in which people attach meaning to their experiences and that forms the context in which change is understood. This construction of reality includes much that is specific to schools but also intersects with wider understandings of education and of specific areas of learning. This means that there is a particular complexity in a learning area such as Languages that has less standing in the overall life of the school. The case for the Languages learning area particularly highlights this complexity because (1) it is seen as less integral to the overall curriculum and overall learning experience of students (notwithstanding the National Goals of Schooling as developed through the Ministerial Council on Education, Employment and Youth Affairs, and the National Curriculum's general capabilities [Australian Curriculum, Assessment and Reporting Authority \{ACARA\} 2013], etc.); (2) it is enmeshed within an ideological framing of education as a monolingual (English-only) endeavour; and (3) there is a lack of a tradition of continuous learning across the entire span of schooling.

Much of the literature to date on the relationship between school culture and curriculum change has focused on the role of school leaders in changing school cultures to facilitate change (e.g. Beaudoin and Taylor 2004; Deal and Peterson 2016; Eilers and Camacho 2007; Engels et al. 2008; Louis and Wahlstrom 2011). This project, however, revealed a quite different dynamic as, although school leaders were involved in deciding to implement the change, as the change was specific to Languages, it was the Language teachers who ultimately drove the curriculum change. This meant that rather than examining the role of school leaders, this article examines the work of teachers as initiators of curriculum change in a context in which the change to the curriculum of the specific subject area has implications for other parts of the school. As those who were driving the curriculum change were Language teachers, they were not typically powerful members of their school communities, but rather were operating from a position of less power as Languages is an area often perceived as having less status in the curriculum as a whole (Liddicoat and Scarino 2010; Liddicoat et al. 2007; Lo Bianco and Slaughter 2009; Scarino and Papademetre 2001). The position of Languages in Australian education represents both the macro-context for shaping the curriculum change involved in the schools and a micro-level, school-internal context that influences how the change is carried out.

The project reported in this article illustrates the complexity of change in schools as well as the necessary catalysts and catalysing processes to engender change. This article examines the ways that culture and the resulting school structures impacted on the processes of curriculum change and how this change unfolded over the course of the project, and then reflects on the resilience of local practices and ways in which these might be challenged.

\section{School culture and the curriculum}

In discussing school culture, Humphries and Burns (2015: 241) define it as "unwritten cultural norms, developed and reinforced by managers, teachers, and students, which impact on teaching practice". School cultures provide symbolic frames for giving meaning to and understanding the meaning of school practices (Helsper 2000); as such, they render actions meaningful and interpretable in the local school context. Curriculum is thus one of the many dimensions of schooling that are given meaning by the culture in which they exist.

Curriculum, whether at the micro level in schools or at the macro level of nations, is an ideological product, and beliefs and assumptions about what it is important for learners to know shape decisions about the content, organisation and evaluation of curricula (Nozaki and Apple 2002). As ideological products, curricula, at the micro level, need to be seen as both a component of and a result of local school cultures that are revealed less through the documents that encapsulate an official curriculum and more within the everyday practices and the common-sense understandings of schooling. Local school cultures of curriculum do not, however, exist independently of larger ideological constructions of curriculum but rather are local instantiations of wider beliefs and norms that shape how knowledge is understood to be organised and valued, both within education systems and outside them.

The ideological nature of curriculum is revealed in a number of different aspects of the curriculum. Ideology is present in what is presented in the curriculum, i.e. what knowledge is considered of value for learners (Apple 2004). It is this aspect of the curriculum that has been most investigated by educational researchers. The idea that some knowledge is considered to be necessary for learners and that other knowledge is not has a profound shape not only on the content of curricula but also how a curriculum is constructed. Curriculum knowledge is not an undifferentiated whole but rather is constructed of areas of knowledge (disciplines), which in turn are ideological products that result from the dividing up of knowledge into discrete spheres, with their attendant academic structures and apparatus (Daston 1998; Shumway and Messer-Davidow 1991). The disciplinary curriculum itself is not a simple assemblage of discrete areas of knowledge but rather is internally structured with some disciplines understood as central or necessary and others as peripheral or optional. This internal structure represents a hierarchy of disciplines which are based on ideologies of the value of certain types of knowledge or of their application in the world. 
The disciplinary curriculum is further constructed by ideologies of membership and legitimacy. Certain people are considered to be responsible for the teaching of a particular discipline because of their qualifications within that discipline, while others are seen as unqualified or less qualified (Daston 1998). Thus, any attempt to change curriculum will be contextualised within the ideological framing of curriculum and the cultural practices that have come to be associated with the construction, teaching and ownership of curricula within the school culture in which the change is to be implemented, and this context can exert influence on the nature and extent of change that is possible. Hopkins (1994: 81) has stated that "School culture is the vital, yet neglected dimension in the improvement process", blaming the failure of school improvement initiatives on a lack of consideration of the importance of the culture of the school. Since then, research on change in schools has drawn attention to the significance of school cultures for the development and sustainability of change (Angelides and Ainscow 2000; Fink and Stoll 2005; Gleeson et al. 2002; Seashore Louis and Lee 2016).

School cultures draw from the wider cultural contexts in which they exist but ultimately are shaped by school actors in interaction with their structural environments (Glover and Coleman 2005; Helsper 2000), which are in turn shaped by the actors themselves. This means that they are local ways of understanding the practices, values and possibilities of educational work. MacGilchrist, Myers and Reed (1995) identified three main ways that school cultures are expressed in the everyday functioning of schools: professional relationships, organisational arrangements and procedures, and curriculum. Each of these elements of school culture relates to particular structural forms that exist in the schools and, because schools tend to be conservative institutions (Fink and Stoll 2005; Hargreaves 1997; Perrenoud 2005), persist because they remain unchallenged and unquestioned. Change therefore has to contend with barriers that may be internal to school processes and culture or external to it (Airasian 1989). Among those barriers internal to the school, the existing school structures may constitute a significant barrier to change and may need to be reformed to permit change to succeed (Godinet 2009).

\section{Design of the study}

\section{Participating schools}

The schools and their cultural contexts and actors involved in the project reported in this paper were as follows:

- Site 1: School A is a public secondary school with over 900 students. It identifies as a school with a strong focus on mathematics and science. The school offers German and Japanese and all Years 8 students are required to study a language. On completion of Year 8, language learning becomes an elective, which if chosen must be studied for a full year. In adopting a model of 'a lesson a day', discussions took place to decide where the additional time would come from. Following discussions of the potential use of pastoral care time and additional lessons before or after school, it was decided that the additional time would need to come from within the regular program. This meant identifying another learning area prepared to share one lesson per week. A major consideration in determining the learning area was the expertise of the Languages staff and, given that their regular programs included some aspects of geography and history, the decision was made to work from the Humanities.

- Site 2: School B is an independent, $\mathrm{K}-12$ (Kindergarten to Year 12) girls' school. The school is an accredited International Baccalaureate school that has a language requirement throughout primary and middle school. It offers French from the beginning of primary school (Years R [Reception]-2), Japanese in Years 3-5, and both languages as a 'taster' course in Year 6, with a choice between French and Japanese from Year 7. The school opted to implement Model 1 by increasing the existing one Japanese lesson (50 $\mathrm{min}$ ) per week to a lesson per day at Years 4-6 for a single cohort of students. The initial intention was to commence with Year 4 and then continue to offer the model, increasing the offering with each year of the project. Once the additional time was agreed, it then had to be found in the timetable, and while preliminary discussions considered the use of pastoral care time or lessons outside regular school hours, it was decided to take the time from the mainstream class program.

- Site 3: School C is a public metropolitan secondary high school with around 1500 students. It is accredited to offer the International Baccalaureate Middle Years Program, and has a long-standing commitment to Languages learning. It currently offers Chinese, German, Japanese, Italian and Modern Greek from Years 8 to 12. For several years, the school has had an interest in offering an 'immersion program' as a means of enhancing learners' language capabilities, and accordingly the school opted to implement Model 3 by teaching the Humanities curriculum in Italian for a single cohort of Year 8 students. The school's leadership was firmly committed to a successful specialised language program and they recognised that this required additional curriculum time and resourcing to be sustainable.

\section{Research design}

The overall methodology of the study was a qualitative collective case study. This is because of the contextual nature of 
the work and the developmental orientation that was necessary to implement and evaluate changes in models of provision. The process involved the selection of the sites through an expression of interest process, in which they nominated one of the proposed models and indicated how it would be developed in the school. The proposed models were:

- Model 1: Primary or junior secondary program with $1 \mathrm{~h}$ or one lesson per day of language instruction, with significant content; the content may be drawn from other areas of the curriculum. (Sites 1 and 2)

- Model 2: A Content and Language Integrated Learning (CLIL) program in which one learning area was taught through the target language. (Site 3)

The exact form that each model was to take was left to internal decisions made by the schools. To ensure that the proposals were intended as whole-of-school initiatives, each expression of interest was submitted jointly by the principals and language teachers and needed to show evidence of consultation within the school. Each school had to make a 3-year commitment to the curriculum initiative it developed, with clear support and evidence for sustainability of the model over time.

\section{Data collection}

Within each site, there were cycles of collaborative planning (involving teachers, school leadership and the research team), implementation and analyses, including a contextual analysis of policies and structures, collaborative curriculum planning and implementation, planning of interventions relevant to each site, monitoring, and ongoing evaluation and annual reporting. Interviews were conducted with participating teachers, school leaders and students on a continuous basis, gathering each participant's perspectives on the process of change over time. The collaborative planning provided opportunities for the researchers to document the processes put in place in each school to change the teaching and learning of Languages, the practices of each school in working towards change, and the ways that members of the school responded to the changes. As the project developed, these practices and responses became one of the focuses of the discussion between various school actors and the researchers. Structural data were also collected through an analysis of school profiles, including information about the school context and learner groups. The researchers also collected and analysed curriculum data, including program documentation, resources, student work samples, tasks and assessment data, and teacher and student evaluation data.

\section{The impact of school structures of curriculum change}

\section{Timetables as structures of learning}

Timetables are structures designed to organise learning over time. While timetables are designed to facilitate learning, they can come to be powerful structures that shape school cultures and have an impact on what can be done in schools (Fink and Stoll 2005).

\section{Timetabling practices}

Timetabling emerged as the most significant structural constraint on change at School A and the particular approach adopted brought the role of timetables as structures into focus in very strong ways. In School A, in order to secure an additional lesson per week, the Languages learning area had to acquire a lesson from another learning area. This was done through a negotiation with the Head of Humanities for the Language teachers to share the teaching of the Humanities curriculum in exchange for the lesson. The Language programs therefore taught parts of the Humanities curriculum in German or Japanese, while the remainder of the curriculum was taught by Humanities teachers in English.

One significant problem, which occupied a considerable amount of the time of the Deputy Principal when the model was first implemented, was the timetabling of the extra lesson. This became problematic because the process of timetabling was done using a fixed computer program and a combination of the limitations of the program and the compounding effect of the school timetabling practices made this extremely complex. A problem arose in changing the timetables due to the way the program used home groups as the basis for timetabling. Classes were assigned to one of seven lines, and these lines were also used to assign teachers and to develop teachers' workloads. Adding a lesson to the Language program therefore required a class that was neither taught on the same line that the Language teacher was teaching nor in the same line in which the class was located. In the first year of the project, this proved to be very difficult to organise for the two Year 8 classes as the line structure itself is not flexible. The problems were increased due to the prevailing practices of timetabling, as Year 8 classes were traditionally the last timetabled. The school began by timetabling senior secondary classes in which students were preparing for the senior secondary certificate including external examinations: "we prioritise from the higher year levels down" (Interview, Principal). The rationale for doing this was parental pressure: "that's the business end of things where parents are going to say 'how does my kid exit from here?"' (Interview, Deputy Principal). Years 9 and 10 classes were timetabled next to allow English, Maths and Science to be timetabled in blocks 
to allow for streaming. Year 8 was therefore the last year level to be timetabled and scheduling Year 8 classes had been considered as a way to solve timetabling issues that resulted from earlier timetabling decisions: "it's with our Year 8s that we do our shuffling around to fix our staffing clashes" (Interview, Deputy Principal). This means that introducing complexity in the timetabling of Year 8 not only created problems for Year 8 classes but removed the existing ways of resolving other timetabling problems. Allocating an extra lesson on another line therefore required significant reshaping of timetabling across year levels.

Finally, timetabling practices meant that it was impossible for the additional lesson per week to result in a lesson per day as all lines had to have a double lesson during the course of the week to provide longer lessons needed by 'practical subjects' such as technical studies, physical education and art. This meant that, even though it was possible to give Languages an extra lesson, it was not possible with the current timetable structure for any subject to be taught every day as there must be at least one double lesson within the week.

Timetabling was also cited by the school as the reason that the model could not be applied in Year 9 as well, although this had originally been envisaged. The source of the problem in Year 9 included the same issues as for Year 8 but the introduction of electives in Year 9 created additional problems as students were required to choose six semester-long elective subjects, although if they chose German or Japanese they were required to commit to a full year, leaving only four other electives. In the third year of the project, the school reduced the number of electives that Year 9 students could take to four in order to increase hours for Maths and Science in line with the requirements of the Australian Curriculum. The selection of electives meant that it was impossible for the Year 8 Language students who had received the additional lesson to form a single 'streamed' cohort in Year 9 as Language students also needed to be grouped for other electives and therefore the language classes needed to be blended because of the reduced number of learners. Home groups were no longer the key organiser at Year 9 as students were not treated as a block but went in various directions due to their electives. The rigid structures of the computer-generated timetable meant that the model was considered onerous by school leaders who had to resolve the timetabling problems. Ultimately, the network of considerations and the established culture and practices related to developing the timetable and the values associated with its development led the school to question the sustainability of the model.

\section{Timetabling and teachers' work}

Although timetabling problems were most significant at School A, the other case study schools also had to consider timetabling as an element of their curriculum change. At
School B, the model adopted was to provide one lesson a day in Japanese and this meant that these lessons for a 'specialised' area had to be taken from the mainstream primary school program. Because workloads are closely correlated with timetables, the reduction of the class teachers' direct teaching time meant problems with their workloads and concerns among them regarding what tasks they would be allocated instead. This was made more complex initially because, after consultation with parents, the school made the intensive Japanese classes optional, with other students continuing to receive one lesson a week. Because the timetable for Year 5 scheduled all students for one lesson per week of language study, the intensive Japanese program was required to continue to offer one 'common' lesson for all students, and the additional four lessons only for students who had opted-in to the 'intensive' program. During the additional lessons, the other 'non-intensive' class worked with one of the class teachers on a separate program, while the other class teacher attended the intensive classes. The requirement for the 'overlapping' lesson in which both intensive and non-intensive students were combined created a number of issues. Firstly, the gap in learning between the two groups became increasingly marked each week despite the teachers' efforts to support progress for all students. A second issue that emerged was trying to provide a coherent program for the non-intensive students. The Japanese teachers addressed this issue by providing two parallel programs: one 'unit of work' for the shared day and another for the intensive days.

In the program's second iteration, the intensive program was factored into the timetabling exercise from the start and a single 'line' with five 50-min lessons per week, an overall increase in time on task, was allocated. However, this created a further problem in that, due to the fortnightly rotation of the timetable, the shared lesson fell on two different days; hence, the intensive program did not operate on those days, resulting in the program being offered on only nine days out of ten. In the third year of the project, the intensive class continued but without the overlapping lesson as the non-intensive students began studying Mandarin as a 'taster' course prior to all students deciding in Year 7, the final year of primary school, which language (French, Japanese or Mandarin) they would study in the secondary school. This meant that the Year 6 Japanese language program had, for the first time, operated as a wholly intensive program for one class of students.

While the model adopted by School C was ultimately less complex for timetabling than that in the other two schools, there were nonetheless timetabling considerations that had to be addressed. The school operates with a seven-line timetable in which Years 8, 9 and 10 students have 200 min per week of Languages, Mathematics, Science, English and Humanities, and two other lines are shared by Health and Physical Education, the Arts and Technology. In order to offer the 'immersion' model, there was in fact no change needed to the 
timetable and it simply meant that the Humanities class would be taught through the medium of Italian. There were some minor considerations to ensure that the Italian-speaking Humanities teacher was available to teach the class and that the teacher of Italian was also allocated the same class (which was also the same home group). These needs produced complexities relating to when teachers were scheduled to teach, and required that Humanities classes were given preference in timetabling approaches: "with Humanities because there are so many classes, you could factor that in first for, say, [name of Humanities teacher]. And then build the other classes around them" (Interview, School C project leader).

The project revealed that timetabling practices have a significant impact on what is possible in change in schools. Where changes fit well with existing ways of structuring timetables, such changes appear to cause little difficulty and seem to be sustainable within existing structures. Where the change requires modification of timetables, however, the modifications constitute significant barriers to change and may ultimately lead to change being unsustainable, as was ultimately the case at School A. In all of the schools, there was a constellation of forces that (re)produced and sustained the structures, which tend to become fixed and impact on all aspects of the curriculum. These structures, which are designed to enable teaching and learning, can thus become barriers to change and indeed restrict learning, even when change is desired. Moreover, the functioning of such structures becomes an invisible part of school culture that is not understood as shaping possibilities.

\section{Curriculum structures}

The division of the curriculum into lines of a timetable seems to be related to a view that curriculum is understood in terms of contact hours between a teacher and a class, and curriculum becomes framed as 'territory' that belongs to particular learning areas or subjects (Priestley 2011). The idea of lines in the timetable appears to have been reified by teachers as curriculum silos and this has worked against the idea of shared responsibility for learning within and across curriculum areas and between teachers. In School A, such shared arrangements had not been a feature of the organisation of teaching prior to the adoption of the Humanities-Languages arrangement. This seems to have solidified the idea that a curriculum consists of a fixed number of lessons taught by one teacher and a corresponding loss or gain of curriculum time being seen as the outcome of an integrated, interdisciplinary approach. The fact that the Language teachers tended to integrate the Humanities component of their teaching across the whole of their time with the students, in fact spending more than a single lesson on it, appears to have meant that their contribution to teaching Humanities was less visible to the Humanities teachers and, rather than being seen as a gain, it contributed to their sense of loss. It was also a matter of who belongs in the territory, i.e. the language teachers were not recognised as legitimate Humanities teachers by their colleagues but were rather identified solely through their attachment to the Languages area.

The rigidity of the timetabling system, the way it interacts with other structures within the culture of the school, and the way that it has been used in the school seem to have worked against collaborative understandings of teaching and learning. The sense of loss created opposition to the introduction of the model from Humanities staff that had to be managed both within the Humanities team by the coordinator and by the school principal. Wubbels and Poppleton (1999) note that a positive response to change is more likely when teachers themselves have had an opportunity to develop the change. At School A, the change had been driven by the Languages teachers in consultation with the Humanities coordinator, but other Humanities teachers had not been involved in discussions and perceived the change as externally imposed. The resulting perception of the model may therefore also be associated with the ways that the change has been planned by the school. In order to ease the tensions, the Principal established an agreement from both the Humanities and the Languages learning areas that each would in effect contribute one lesson to the interdisciplinary model. This meant that both learning areas could be seen as having 'lost' or 'gained' curriculum time, although in practice this meant no real change in the way teaching was organised.

The change also seemed to be affected by the ways the secondary school curriculum as a whole was perceived. There was a sense within the school culture that some subjects are core and others are non-core, and core subjects are given priority in decision-making (c.f. Paechter 2000). The Principal referred to English, Maths and Sciences as the "major key learning areas" and stated that these were "guaranteed through to Year 10" (Interview, Principal). The school believed that its areas of strength were Maths and Science and was proud of students' achievements in this area. Other areas such as History, Health, Physical Education and the Arts were required to Year 9 and beyond based on the Australian Curriculum. The only learning area in Year 8 that was not required in Year 9 was Languages, which marks this learning area as the most marginal/optional of the whole curriculum.

At School B, the increased time from one to five lessons per week created two major curriculum issues. Firstly, it raised questions about the nature of the Japanese curriculum and expectations in terms of student learning in a more intensive program. The increased expectations prompted a complete redevelopment of the Year 5 and 6 Japanese programs. The content was not only increased but became different in nature, with the teachers including explicit teaching of Japanese script and a greater focus on intercultural understandings, higherorder thinking and reflection. According to the Japanese teachers, these dimensions of language learning were not 
achievable within one lesson per week, but the increased time enabled a concept-based programming approach with more robust and meaningful connections to the school's International Baccalaureate Primary Years Program. The Japanese curriculum became seen as more worthwhile as it aligned better with the valued learning in the whole school curriculum: "So [the Japanese teachers] had tied in particular aspects of the Japanese to our inquiry which was about how people can take action to help others. So there was certainly a link there and I would say a much stronger link" (Interview, Classroom teacher).

The change also had an impact on the mainstream curriculum planned by the class teachers. In each year, there are key priorities in the program such as Year 4 preparation for the national, standardised literacy and numeracy test (NAPLAN [National Assessment Program - Literacy and Numeracy]), Year 5 drama production and camp, and Year 6 leadership skills and peer support. These aspects were considered to be integral learning, and in order to make the additional time for the intensive Japanese, these programs had to be redesigned and some aspects were reduced or removed altogether. As one teacher put it, "It sort of knocked out language lessons for the week, as in English, and it knocked out a couple of inquiry lessons for the week so we had to jam our inquiry into a very small space of time." Another teacher reported removing "fun" activities such as making pancakes for Shrove Tuesday. Whole-school activities such as the swimming carnival were considered to add to an already compressed program. As one teacher stated, "It's very tight. So we feel very pushed in terms of getting our curriculum done. ... And (you have to consider) what has to go and how you have to juggle other lessons, look at the relevance of how you go about teaching other things to fit it into the more constrained time frame." Such comments reveal a sense that the curriculum change was a loss of time for the mainstream curriculum.

A further consequence of the intensive Japanese program arrangements was the issue of what to do with the students who were not participating in the program. The class teachers felt constrained in relation to what alternative program they could offer that did not either waste time or advantage the nonparticipating group. As one teacher stated, "It was very hard to find something that was not going to cause issues with parents because if you had the issue of doing something really whizz bang exciting with the non-Japanese group, then we've got the parents going 'Well hang on my daughter is missing out.' We had to juggle that very carefully." The decision was therefore made to offer a general study skills and literacy program including creative thinking and research into aspects of culture such as national identity and immigration.

At School C, which like School A combined Languages with Humanities, the issues were quite different because the model adopted of teaching the whole of the Humanities curriculum in Italian (in addition to the regular Italian language program) did not reduce the time allocated to Humanities. Moreover, the teacher responsible for teaching Humanities in Italian was a member of both the Italian faculty and the Humanities faculty and so the Humanities component was not viewed as being allocated to another disciplinary area. In this way, the curriculum change corresponded to the prevailing understanding of curriculum structures rather than challenging them.

Given that curriculum was the main focus of the change, to which the schools subscribed in expressing interest in the project, it is interesting that curriculum itself also constituted a key structural problem in implementing the changes. The attempt at developing a collaborative curriculum across Languages and Humanities failed to be seen as a collaborative endeavour because it did not fit pre-existing understandings of the structure of the curriculum. Rather than viewing the curriculum in terms of what was being learnt by the students, the prevailing curriculum structures (including timetabling) instead focused on hours of teaching and, from this perspective, the change was understood primarily in terms of loss or gain of teaching time. This view of curriculum is supported by macro-level curriculum structures, such as the Australian Curriculum of which the indicative hours (for writing the curriculum) were often cited as the basis for curriculum planning and program implementation in each of the schools.

\section{Curriculum planning}

As the curriculum changes in all of the schools involved both the Languages area and other areas, collaborative planning was an important factor in developing the change and creating a sense of an integrated curriculum (Thousand et al. 2006). In each school, this collaborative planning worked differently, but the usual experience was that such planning was difficult due to the ways that curriculum planning was normally framed and conducted.

At School A, it was necessary to develop a curriculum for Humanities that could be taught by different teachers as the Languages teachers took responsibility for only part of the overall Humanities program. This collaborative planning, however, was not built into the curriculum change process and it was left to the Languages teachers to initiate meetings with Humanities staff. The usual process for curriculum planning in the school had been discipline based; teachers from outside the discipline were not included. At schools, subjects often provide the main frame and structure for professional dialogue between teachers (Priestley 2011), but a rethinking of curriculum that crosses subject boundaries may prove problematic because the idea of 'subject' as the structure for professional dialogue may preclude other discussions. Planning in School A continued to be done using this model and the lack of a forum for professional discussion made it difficult to develop a common culture between Languages and 
Humanities teachers (c.f. James and Connolly 2000). This meant that the Languages teachers were not considered as legitimate members of the team planning the Humanities curriculum even though they had responsibility for teaching part of it. There was no forum for collaborative decision-making about the Humanities curriculum in its new conceptualisation and the communication and negotiation between staff primarily occurred through ad hoc discussions, initiated by individuals, outside of mainstream school processes such as faculty meetings. In this way, the flexibility needed for collaborative planning was created by individuals because structures did not allow for it, but, at the same time, because such planning was not a part of formal structures, it was not particularly valued or felt necessary by all teachers. In particular, the lack of structures to support collaborative planning seemed to perpetuate the views of those teachers who saw the change as encroaching on territory.

For the Languages teachers, it was a priority to negotiate the content to be taught and share their progress within the time allocated to Humanities taught in German and Japanese with their Humanities colleagues. These processes of negotiation varied over the 3 years depending on the staff involved and how engaged individual Humanities teachers were with the change, although generally the communication and sharing of resources was constructive. However, it was rarely the case that Humanities teachers kept the Language teachers up to date with what was happening in their Humanities classes: "I make a point of going to [Humanities teacher] and saying I am planning to do this, what do you think? If I did not do that I would not know what he was teaching" (German teacher: team meeting). One Languages teacher reported talking to the students about their Humanities classes and using this input to adjust her planning of the Humanities content. The collaboration was therefore one-way with the Languages teachers seeking out and making opportunities to plan their work with the Humanities teachers. In part, this appears to be the result of the impression that the classes taught in German and Japanese were lost time for Humanities and thus of collaborative planning not being relevant, at least for the Humanities teacher.

At School B, the curriculum design and implementation issues raised for both the Japanese and class teachers reflected a broader challenge in the primary school related to the culture of curriculum planning and the 'struggle' to facilitate shared planning. As the Head of Junior School said,

This is exactly the same problem we have with every specialist teacher trying to get them to sit down with the year level teachers and plan units of inquiry. And in the end it is the year level teachers who plan the units of inquiry and they pull these specialist teachers in as they can ... So we have parallel, parallel, parallel, instead of link, link, and separation. I think it's a school thing. It's a time thing.
She also expressed a desire to improve the culture of curriculum planning in future, "there has to be time made for both parties, from the start so that everyone's involved in planning ... This is the way to make any program like this work is to pick up the conceptual links." Thus, the Head of the Junior School recognised that a change in the school's culture of curriculum planning was needed to enable the change.

At School C, curriculum planning was conceived of in terms of both the Humanities (in Italian) and the regular Italian (second language) program working in tandem to provide maximum language learning. From the start, there was the principle of collaboration, with the regular Italian program 'front-ending' the language content necessary for students to develop vocabulary and classroom routines suitable to the immersion-style teaching and interaction in particular. This meant, therefore, that the programs for both learning areas needed to be developed in collaboration such that the scope and sequencing and assessment were complementary. As both teachers were teachers of Italian, it was relatively easy for them to develop a shared understanding of the curriculum in each area, but even so this involved finding ways of meeting that were outside the established planning structures of the school. Even though both teachers participated in the Languages faculty meetings, this time could not be used for 'other' activities, as it focused on matters common to all languages. In structural terms, the major challenge was to find opportunities where staff in the Humanities and the Italian programs could meet regularly (i.e. each week) in order to plan together. There was (at the time of the project) no specific time allocated for interdisciplinary or shared planning, hence the staff used funds from the project to release them from classes in order to plan together. While the project funds were intended for such use, the experience highlights the lack of structural arrangements within schools to support interdisciplinary planning.

All of these curriculum changes introduced some degree of interdisciplinary planning. This proved difficult within the structures of the schools as planning was structured along disciplinary or classroom year-level lines. Any interdisciplinary planning processes that were developed tended to be ad hoc and in one case required financial support from the project to organise. Such planning was, therefore, done outside existing structures and did not generate robust new structures for planning, despite all of the teachers involved in the project recognising the need for it. Hargreaves (1997: 3) states that "the central task in creating a culture of educational change is how to develop more collaborative working relationships". In each of the schools studied here, however, existing school structures constrained the possibilities for developing such 
relationships, and it would seem even backgrounded their significance.

\section{Staffing structures}

The schools in this project were affected to a certain extent by requirements emerging from outside in relation to their use of human resources, and these requirements influenced how the change progressed. In each case, human resources requirements created a background context that needed to be resolved in order to implement the curriculum change.

At School A, the teachers of Japanese and German added one lesson to their teaching loads. This meant that the corresponding Humanities teachers had one fewer lesson in their teaching load. This created a situation in which the Language teachers' teaching loads could not be adjusted, in part because teachers' workloads were allocated as blocks of time teaching a particular subject at a particular year-level and allocating individual parts of such blocks was not possible in the existing workload structures. The adjustment was made by reducing the yard duty of the two Language teachers, but the result was that the teachers' workload was still above the required allocation. The teachers accepted this as a consequence of their desire to develop their program, but recognised that it was not a long-term solution; during the 3 years of the project, no solution was identified by the school.

The situation at School B was less complex but the proposed model presented challenges in terms of staffing, as the specialist Japanese teachers needed to be available for an increased period and their availability to teach in the senior school needed to be taken into account to avoid timetable clashes. Another issue was that when the Japanese teachers were teaching the intensive program, the class teachers were not teaching, thus increasing their non-contact time and creating a workload parity issue. The additional staffing costs were initially borne by the school but this was not considered sustainable in the longer term. At the conclusion of the project, the school ratified a new Languages policy in which all primary students study four lessons per week and the class teachers have been reassigned to other tasks such as literacy support, taking relief lessons or teaching classes in which they have a specialisation, e.g. Drama.

At School C, staffing issues had other consequences. Here, the major concern was to ensure that the size of the immersion class was consistent with other classes, due to staff-student ratio formulas established in the industrial agreement. This meant that in order to implement the new program, the school had to recruit an adequate number of students to make a full class. This requirement delayed the implementation of the model, as the enrolments initially did not meet the required cut-off levels and the model instead became a 6-week pilot program. Recruitment problems remained challenging, and in the second year the program was implemented for one semester only and this continued in the third year; however, after the project concluded the program was then offered for a full year.

The staff workloads and time allocations were understood and managed by schools in different ways. The independent school, School B, appeared to have greater flexibility in dealing with these than the other schools, but, nonetheless, the schools tended to adopt ad hoc arrangements in which disparities were allowed to exist in order to allow the change to progress, although in the case of School C, staffing structures initially prevented full implementation. Where ad hoc solutions were adopted, these usually persisted for the duration of the project and seemed to represent unsolvable structural problems. Where schools were prepared to change their ways of thinking about curriculum and ways of working, they were able to generate solutions, e.g. in School B. Such rethinking, however, was often prompted externally by the project team attending to the way structures impacted on learning and creating a forum in which these could be problematised and worked through.

\section{Conclusion}

This study has shown that school cultures and the structures they generate have a significant impact on processes of curriculum change, often as hidden or unacknowledged factors shaping what is possible in schools. Structures are achieved through complex processes of consensus building, and made more so by the role that power relations in schools have in the evolving consensus. Once established, these (usually hardwon) structures become naturalised as the culture of the school - the way things are done. Curriculum change is made difficult because of structures, and these structures come to represent 'how thing are done here' (i.e. established culture). These structures become firm, fixed and unquestioned, and over time (and for convenience) become residualised, shaping possibilities for learning and teaching, the use of time, human resources, etc., and constraining change. As residualised elements of the school culture, they become powerful forces for inertia (Fink and Stoll 2005).

School structures interact with other elements of school culture and in this study one of the most powerful forces sustaining structures was the prevailing ideologies around education. These ideologies were manifested in the ways that particular learning areas are prioritised within the curriculum and the discipline-based views of learning. This is because, first, the structures that are in place have been elaborated within the overall ideological framing that exists in the school and the structures can be seen as ideological products that support the dominant view of educational forms and priorities. The ideologies that allocate priorities to some curriculum areas over others can create barriers for curriculum change in areas 
such as Languages, which are not seen as ranking high in the list of priorities. This is further reinforced by a disciplinebased ideology of curriculum structures in which overall student learning is less visible than the allocation of time and teachers to particular learning areas. Where a low-status learning area changes in ways that have an impact on other more highly valued areas, these changes may be seen as transgressing. Where curriculum boundaries are solid, this transgression is understood as not only disruption of other learning areas but also as a territorial invasion.

Because structures are rigid, ideological products that have become naturalised within school cultures, change that is not congruent with existing structures is difficult, because it is transgressive of those existing structures. The instances of curriculum change discussed in this article have not been congruent with the structures that existed in schools and required flexibilities that these structures did not automatically provide. Where this was the case, these flexibilities were created by the people most invested in the change; that is, the Languages teachers who created flexibility through informal, ad hoc ways of working with and around the existing structures. Because Languages is seen as a low status discipline, however, the flexibilities they put in place were not always taken up by their colleagues.

In such contexts, school leaders play significant roles in helping to address the constraints within existing structures (Fernandez 2000). Where school leaders recognised the problems structures caused, it was possible to develop new structures that supported the change and made it sustainable, as in School B, which ultimately adopted a new language policy for the school, and in School C, where existing structures were modified sufficiently to allow Humanities to be taught in Italian. Strategic leadership can facilitate change - if the vision for something different is clear and the case can be made with staff. Leaders are crucial to working with school values and culture - and the power given to structures. Where school leaders did not resolve the structural impediment, as in School A, it was left to Languages teachers themselves to broker the process, but without the necessary power to influence the structures, and ultimately rendering the change unsustainable.

Ultimately, however, change is not structural but conceptual and slogans such as 'change as culture', 'change through leadership', 'change management' and 'leaders as change agents' do not capture this difference. While changing school structures is a school-internal process, this project showed that there was a need for the external perspective brought by the researchers in effecting change (Timperley 2008). It was often the researchers who focused on the constraints of school structures and this helped to dislodge existing perspectives of these structures as neutral organising features of the school's work. Until structures are seen as social and cultural constructs rather than as the natural way of working, they are not available for critique and thus for change. This project was designed for ongoing dialogue and experimentation within schools over a 3 -year period, involving teachers and school leaders and thus providing a forum in which structures could be made visible, discussed and critiqued in relation to the goals of the proposed curriculum changes. The researchers also provided forms of support and collaboration that enabled such debates to occur and, as such, the research project and the researchers involved were able to act as catalysts for change and were accepted as such. Change and innovation in schools ultimately involves processes of reflection not only on the change or innovation to be implemented but also about the contexts in which the change will be enacted. Such reflection can be enhanced by the presence of external participants, who are not actors within the school culture and have different investments in change and continuity of practice.

Open Access This article is distributed under the terms of the Creative Commons Attribution 4.0 International License (http:// creativecommons.org/licenses/by/4.0/), which permits unrestricted use, distribution, and reproduction in any medium, provided you give appropriate credit to the original author(s) and the source, provide a link to the Creative Commons license, and indicate if changes were made.

\section{References}

Airasian, P. W. (1989). Institutional barriers to school change. In W. G. Rosen (Ed.), High-school biology today and tomorrow (pp. 252265). Washington, DC: National Academy Press.

Angelides, P., \& Ainscow, M. (2000). Making sense of the role of culture in school improvement. School Effectiveness and School Improvement, 11(2), 145-163.

Apple, M. W. (2004). Ideology and curriculum. New York \& London: Routledge Falmer.

Australian Curriculum, Assessment and Reporting Authority (ACARA) (2013). Curriculum Design Paper 3.1. Sydney: ACARA.

Beaudoin, M.-N., \& Taylor, M. (2004). Creating a positive school culture: How principals and teachers can solve problems together. Thousand Oaks, CA: Corwin Press.

Daston, L. (1998). The academies and the unity of knowledge: The disciplining of the disciplines. Differences. A Journal of Feminist Cultural Studies, 10, 67+.

Deal, T. E., \& Peterson, K. D. (2016). Shaping school culture. San Francisco, CA: Jossey-Basse.

Eilers, A. M., \& Camacho, A. (2007). School culture change in the making. Urban Education, 42(6), 616-637.

Engels, N., Hotton, G., Devos, G., Bouckenooghe, D., \& Aelterman, A. (2008). Principals in schools with a positive school culture. Educational Studies, 34(3), 159-174.

Fernandez, A. (2000). Leadership in an era of change: Breaking down the barriers of the culture of teaching. In A. Harris, C. Day, D. Hopkins, M. Hadfield, A. Hargreaves, \& C. Chapman (Eds.), The life and work of teachers. International perspectives in changing times (pp. 239-255). London: Falmer.

Fink, D., \& Stoll, L. (2005). Educational change: Easier said than done. In A. Hargreaves (Ed.), International handbook of educational change: Extending educational change (pp. 17-41). Dordrecht: Springer. 
Fullan, M. (2016). The new meaning of educational change. New York, NY: Teachers College Press.

Gleeson, J., Clifford, A., Collison, T., O’Driscoll, S., Rooney, M., \& Tuohy, A. (2002). School culture and curriculum change: The case of the leaving certificate applied (LCA). Irish Educational Studies, 21(3), 21-44.

Glover, D., \& Coleman, M. (2005). School culture, climate and ethos: Interchangeable or distinctive concepts? Journal of In-Service Education, 31(2), 251-272.

Godinet, H. (2009). Observer et évaluer l'innovation. In C. Delahaye, M.C. Derouet-Besson, \& H. Godinet (Eds.), Observer l'innovation, un cas d'école innovante (pp. 11-32). Lyon: Institut National de Recherche Pédagogique.

Hargreaves, A. (1997). Rethinking educational change. In M. Fullan (Ed.), The challenge of school change (pp. 3-32). London: Routledge Falmer.

Helsper, W. (2000). Wandel der Schulkultur. Zeitschrift für Erziehungswissenschaft, 3(1), 35-60.

Hopkins, D. (1994). School improvement in an ERA of change. In P. Ribbins \& E. Burridg (Eds.), Improving education: Promoting quality in schools (pp. 74-91). London: Cassell.

Humphries, S., \& Burns, A. (2015). 'In reality it's almost impossible': CLT-oriented curriculum change. ELT Journal, 69(3), 239-248.

James, C., \& Connolly, U. (2000). Effective change in schools. London: Routledge Falmer.

Liddicoat, A. J., and Scarino, A. (2010). Future possibilities and directions in languages education. In A. J. Liddicoat and A. Scarino (Eds.), Languages in Australian education: problems, prospects and future directions. Newcastle-upon-Tyne: Cambridge Scholars.

Liddicoat, A. J., Scarino, A., Curnow, T. J., Kohler, M., Scrimgeour, A., \& Morgan, A.-M. (2007). An investigation of the state and nature of languages in Australian schools. Science and Training, Canberra: Department of Education.

Lo Bianco, J., \& Slaughter, Y. (2009). Second languages and Australian schooling. Camberwell, Vic: Australian Council for Educational Research.

Louis, K. S., \& Wahlstrom, K. (2011). Principals as cultural leaders. Phi Delta Kappan, 92(5), 52-56.
MacGilchrist, B., Myers, K., \& Reed, J. (1995). The intelligent school. London: Paul Chapman.

Nevalainen, R., Kimonen, E., \& Alsbury, T. L. (2017). Educational change and school culture. In E. Kimonen \& R. Nevalainen (Eds.), Reforming teaching and teacher education: Bright prospects for active schools (pp. 195-224). Rotterdam: SensePublishers.

Nozaki, Y., \& Apple, M. W. (2002). Ideology and curriculum. In D. Levinson, P. Cookson, \& A. Sadovnik (Eds.), Education and sociology: An encyclopedia (pp. 381-385). London \& New York: Routledge.

Paechter, C. (2000). Changing school subjects: Power, gender and curriculum. Buckingham: Open University Press.

Perrenoud, P. (2005). Peut-on réformer le système scolaire? In D. Biron, M. Cividini, \& J.-F. Desbiens (Eds.), La profession enseignante au temps des réformes (pp. 37-48). Sherbrooke, QC: Éditions du CRP.

Priestley, M. (2011). Schools, teachers, and curriculum change: A balancing act? Journal of Educational Change, 12(1), 1-23.

Scarino, A., \& Papademetre, L. (2001). Ideologies, languages, policies: Australia's ambivalent relationship with learning to communicate with the other. In J. Lo Bianco \& R. Wickert (Eds.), Australian policy activism in language and literacy (pp. 305-324). Melbourne: Language Australia.

Seashore Louis, K., \& Lee, M. (2016). Teachers' capacity for organizational learning: The effects of school culture and context. School Effectiveness and School Improvement, 27(4), 534-556.

Shumway, D. R., \& Messer-Davidow, E. (1991). Disciplinarity: An introduction. Poetics Today, 12(2), 201-225.

Thousand, J. S., Villa, R. A., \& Nevin, A. I. (2006). The many faces of collaborative planning and teaching. Theory Into Practice, 45(3), 239-248.

Timperley, H. (2008). Teacher professional learning and development. Geneva: UNESCO/IBE.

Wubbels, T., \& Poppleton, P. (1999). Knowledge about change and its effects on teachers. In M. Lang, J. Olson, H. Hansen, \& W. Bünde (Eds.), Changing schools/changing practices: Perspectives on educational reform and teacher professionalism (pp. 149-156). Louvain: Garant. 